\title{
A blueprint for improving undergraduate education in intensive care medicine
}

\author{
Enda O'Connor ${ }^{*}$ and Ignacio Martin-Loeches
}

According to the World Federation of Medical Schools, medical students should have "sufficient knowledge and clinical and professional skills to assume appropriate responsibility after graduation" [1]. Some medical schools fall short of this goal, notably in preparing graduate doctors in their role as first-responders for managing patients with acute illness [2]. In this letter, we propose strategies to help the intensive care medicine (ICM) community address this training shortfall.

Regional variability in the provision and organisation of undergraduate intensive care (UGIC) teaching, previously reported, undermines educational consistency and effectiveness [3]. Findings from our recent mixed-methods study highlight this ongoing issue. Following ethics approval, we surveyed ICM educators in all intensive care units (ICUs) with student placements $(\mathrm{n}=16)$ and conducted semistructured interviews with medical school representatives $(n=6)$ throughout Ireland between December 2013 and February 2014.

Although ICM was mandatory in five medical schools, most placements (13 of 16 ICUs; $81.3 \%$ ) lasted 5 days or less. Five ICUs (31.3 \%) lacked a formal student learning curriculum, and procedural training was largely absent in all units. There was minimal provision for either student feedback or teaching evaluation, and 15 units (93.8 \%) had no formal process for student assessment. Insufficient staffing, funding, and teaching time were the most commonly reported barriers to student teaching.

The ICU is a unique learning environment, offering students clinical diversity and workplace experiences found infrequently elsewhere, while achieving measurable cognitive and procedural learning outcomes [4]. Notwithstanding this, our study of Irish UGIC education (E. O'Connor, 2013, unpublished data), echoing international reports, suggests that its value is not being fully harnessed. How might we improve current practice, thereby preparing students for managing acute illness?

\footnotetext{
* Correspondence: oconnoen@tcd.ie

Department of Intensive Care Medicine, St James's University Hospital, Trinity Centre for Health Sciences, James's Street, Dublin 8, Ireland
}

First, key educational principles underpinning educational design should be applied to UGIC placements. These include clear articulation of expected learning outcomes, a learning curriculum, a description of teaching methods (ideally a combination of bedside, classroom, and eLearning activities), formal evaluation of teaching, and summative student assessment aligned to the expected learning outcomes [5].

Second, clear endorsement by medical schools of the value of UGIC teaching, mainly by providing protected time and resources for teachers, and ensuring appropriate placement duration, should be forthcoming. Our research suggests that the level of institutional support is still a major barrier to effective student teaching.

Finally, we can promote effective and efficient UGIC learning through educational research. This can be either quantitative, using educational interventions and objective measureable outcomes to ask "do students learn in the ICU?", or qualitative research, exploring students' learning experiences, asking questions such as "how do students learn in the ICU?".

\section{Abbreviations}

ICM, intensive care medicine; ICU, intensive care unit; UGIC, undergraduate intensive care

\section{Funding}

No funding was required for either the manuscript or for the study quoted therein.

\section{Availability of data and materials \\ All data reported in the manuscript are held by the primary author in a personal computer and can be made available if required.}

\section{Authors' contributions}

EOC: design of the study, analysis of data, and drafting and finalization of the manuscript. IML: drafting and finalization of the manuscript. Both authors read and approved the final manuscript.

\section{Authors' information}

EOC and IML both have academic appointments and oversee medical student rotations in the Department of Intensive Care, St James's Hospital. EOC has recently completed a Masters of Sciences in Clinical Education, which involved research on the learning experiences of medical students in an intensive care medicine clinical clerkship. 


\section{Competing interests}

The authors declare that they have no competing interests.

\section{Ethics approval and consent to participate}

Ethics approval for the study quoted in the manuscript was obtained from the Faculty of Health Sciences Research Ethics Committee, Trinity College, Dublin, Ireland.

\section{Published online: 27 July 2016}

\section{References}

1. Global standards for quality improvement in basic medical education. In: World Federation of Medical Education. 2015. http://wfme.org/standards/ bme/78-new-version-2012-quality-improvement-in-basic-medicaleducationenglish/file. Accessed 15 May 2016.

2. Tallentire VR, Smith SE, Skinner J, Cameron HS. The preparedness of UK graduates in acute care: a systematic literature review. Postgrad Med J. 2012;88:365-71.

3. Whereat S, McLean A. Survey of the current status of teaching intensive care medicine in Australia and New Zealand medical schools. Crit Care Med. 2012:40:430-4.

4. Rogers $\mathrm{PL}$, Jacob H, Thomas EA, Harwell M, Willenkin RL, Pinsky MR. Medical students can learn the basic application, analytic, evaluative and psychomotor skills of critical care medicine. Crit Care Med. 2000;28:550-4.

5. Dick W, Carey L, Carey JO. The systematic design of instruction. 7th ed. Minneapolis: Merrill Pearson; 2009. 